\title{
Limitations of two frame method for displaying regional left ventricular wall motion in man
}

\author{
D L MARIER, D G GIBSON
}

From Brompton Hospital, London

SUMMARY Regional abnormalities of left ventricular function are frequently determined from superimposed cavity outlines at end-diastole and end-systole. The timing of end-diastole is standardised with respect to the electrocardiogram, but that of end-systole is undefined, and frequently determined by simple inspection. To examine the effect of variation in the timing of the end-systolic frame on apparent regional wall motion, 35 left ventricular angiograms from patients with ischaemic heart disease were digitised frame by frame, and the timing of aortic valve closure and mitral valve opening superimposed on contour displays. In 15 patients, the pattern in the two frame display with end-systole taken as aortic valve closure was similar to that when it was taken as mitral valve opening. In the remaining 20 , however, there were major discrepancies between the two, because of changes in cavity shape during isovolumic relaxation. These shape changes were the result of asynchronous termination of systole in different regions of the ventricle. In addition, there was a significant increase in left ventricular cavity area of $3.9 \pm 1.7$ per cent during isovolumic relaxation, corresponding to an increase in calculated volume of $8 \cdot 1 \pm 4.5$ per cent. Estimates of ejection fraction derived from end-systole taken at endejection were thus consistently greater than those at mitral valve opening. These differences in the apparent pattern of regional wall motion resulting from lack of definition of end-systole are large compared with those reported after intervention angiography, or surgery. Thus, if two frame methods are to be used, the timing of end-systole must be standardised. We suggest that end-ejection be used. Changes of shape during isovolumic relaxation should be considered separately.

Regional abnormalities of left ventricular wall movement are a significant feature of coronary artery disease, so that their detection and documentation by angiography forms an essential part of the assessment of such patients. A left ventricular angiogram, however, contains so much information that it is not usually possible to assimilate it all using purely manual methods. For this reason, it has become customary to demonstrate regional left ventricular wall movement by superimposing end diastolic and end-systolic cavity outlines. ${ }^{1}$ If the only abnormalities of wall movement were those of amplitude, such a display would be adequate, provided that the timing of the two frames was appropriate. In practice, however, this method appears to have limitations. While end-diastole can be determined either with reference to the electrocardiogram or the onset of tension development, end-systole, even in the normal subject, is undefined. In coronary artery disease, the timing as well as the amplitude of wall motion may be Received for publication 24 April 1980 abnormal. In particular, in ischaemic myocardium, the duration of tension development may be prolonged, ${ }^{2}$ so that end-systole occurs at different times in different parts of the same ventricle. We have therefore investigated possible limitations in the two frame technique for displaying regional wall motion arising from this lack of definition of endsystole. We have varied the timing of the endsystolic frame within the period of isovolumic relaxation and have examined the effect on regional wall movement as displayed by the two frame method.

\section{Subjects and methods}

Left ventricular angiograms from 120 patients who had undergone cardiac catheterisation for assessment of ischaemic heart disease were reviewed. Of these, the timing of aortic valve opening and closure was apparent in 35 . In these cases, the cusps were visible within the aortic root. The timing of aortic valve opening was taken as the frame in which the 
cusps had just begun to lift and separate. Complete opening had usually occurred by the succeeding frame. Aortic valve closure was taken as apposition of the cusps, this frame usually being preceded by one showing them in the half closed position. Mitral valve opening was taken as the first frame showing unopacified blood within the left ventricular cavity from the left atrium. ${ }^{3}$

Left ventriculograms were performed during diagnostic cardiac catheterisation. A bolus of $40 \mathrm{ml}$ contrast was injected into the ventricle at $15 \mathrm{ml} / \mathrm{s}$, with the patient in the right anterior oblique position. A film speed of 50 frames/s was used. Ectopic and post-ectopic beats were not studied. Calibration was by means of a grid exposed at midchest level. The left ventriculograms were digitised frame by frame. ${ }^{3}$ The following information was derived:

(1) A continuous plot of cavity area, and volume, derived using the regression equation of Dodge et al. ${ }^{4}$

(2) The time of minimum cavity area.

(3) The change in area and calculated volume between aortic valve closure (AVC) and mitral valve opening (MVO).

(4) Values of ejection fraction, calculated using the frame synchronous with aortic valve opening as end-diastolic, and end-systolic taken as (a) the frame synchronous with aortic valve closure (EF.AVC), or (b) with mitral valve opening (EF.MVO). ${ }^{5}$

(5) A pair of two frame displays, with the enddiastolic outline in both taken as that synchronous with aortic valve opening, and end-systolic as (a) that of aortic valve closure, or (b) of mitral valve opening.

The apparent pattern of regional wall motion on the two displays was compared, and discrepancies between the two were noted. Particular attention was paid to the following.

(a) Reversal of systolic wall motion between the two, that is one display showing regional inward and the other outward movement affecting the same area.

(b) Differences in the regional amplitude of movement between the two displays, amounting to more than $5 \mathrm{~mm}$. This figure was chosen on the grounds that differences of this magnitude, observed as the result of an intervention, would probably be regarded as clinically significant.

The statistical significance of differences between means was assessed, where appropriate, by Student's $t$ test. Linear regression was performed by the method of least squares fit.

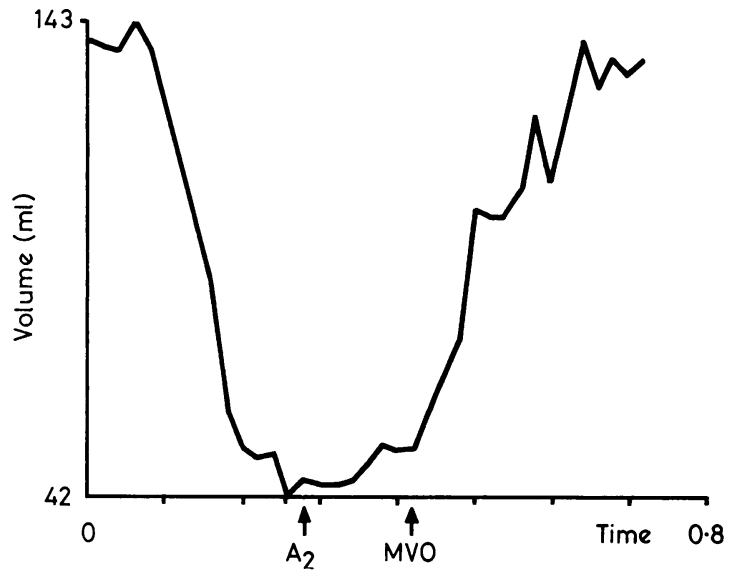

Fig. 1 Normal left ventricular volume plot from a cineangiogram. The timing of $A 2$ (aortic valve closure) and MVO (mitral valve opening) are indicated.

There is an increase in calculated volume between the two.

\section{Results}

\section{(1) CHANGE IN CAVITY AREA AND VOLUME} DURING ISOVOLUMIC RELAXATION

There was a consistent increase in cavity area during the period between aortic valve closure and mitral valve opening (Fig. 1) of $3.9 \pm 1.7$ per cent, which was significantly different from zero $(p<0.001)$. This corresponded to an increase in cavity volume of $8 \cdot 1 \pm 4.5$ per cent. In patients with regional abnormalities of wall movement during isovolumic relaxation, ${ }^{3}$ the increase in area was $4.5 \pm 1.4$ per cent, significantly greater than the value of $3 \cdot 0 \pm 1 \cdot 6$ per cent found in those without such abnormalities $(\mathrm{p}<0.01)$.

\section{(2) EFFECT OF TIMING OF END-SYSTOLE ON CALCULATED LEFT VENTRICULAR EJECTION FRACTION}

As a result of the apparent change in cavity volume between the times of aortic valve closure and mitral valve opening, there were consistent differences in ejection fraction resulting from these differing values of end-systolic volume. The mean value of ejection fraction with end-systole taken as aortic valve closure (EF.AVC) was 68.3 per cent, and as mitral valve opening (EF.MVO) was $59 \cdot 9$ per cent. The corresponding regression equation was:

$$
(\text { EF.MVO })=0.98(\text { EF.AVC })-7.2 \text { per cent }
$$

$r=0.96$, and the standard error of the estimate was 4.9 per cent. The intercept differed significantly from zero $(p<0.05)$. Estimates of ejection fraction 


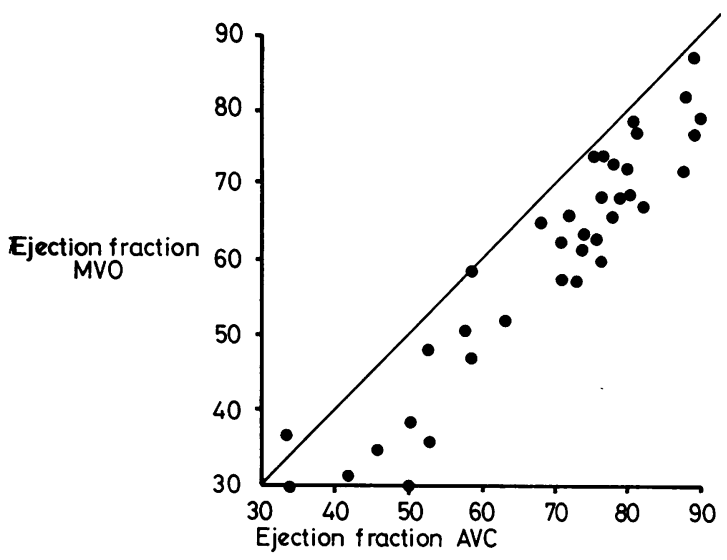

Fig. 2 Comparison of estimates of ejection fraction, taking end-systole as mitral valve opening (MVO) and aortic valve closure ( $A V C)$.

calculated when end-systole was taken as mitral valve opening were thus significantly lower than when aortic valve closure was used (Fig. 2).

\section{(3) DISCREPANCIES IN ASSESSMENT OF}

\section{REGIONAL WALL MOTION}

The two displays, one with end-systole taken as the time of aortic valve closure and the other as that of mitral valve opening, agreed in describing wall motion in 15 patients. In eight of these, contraction pattern was normal, and ejection fraction (AVC) lay between 67 and 87 per cent. In four patients there was generalised hypokinesis, with values of ejection fraction (AVC) between 24 and 57 per cent. In only three of these patients were regional abnormalities of wall movement present, involving the anterior wall in two and the apex in one. In the remaining 20 , however, there were major discrepancies between the two displays (Fig. 3 and 4). In eight, outward movement was shown by one of the
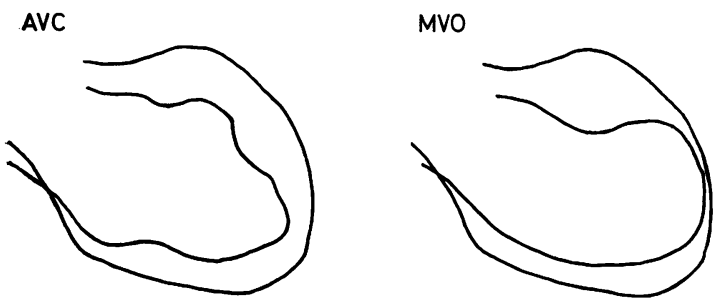

Fig. 3 Comparison of two frame displays of regional left ventricular wall motion from a single cardiac cycle. End-diastolic outlines are identical, but end-systole was taken as AVC on the left, and MVO on the right. Wall motion on the left appears normal, but hypokinesis is demonstrated on the right.
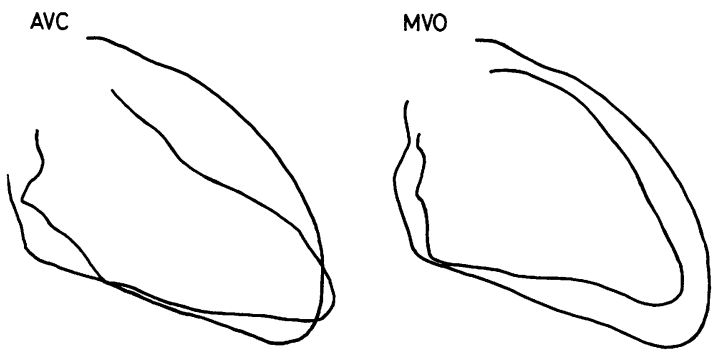

Fig. 4 Comparison of two frame displays from a single beat. Layout as Fig. 3. Aneurysmal movement at the apex on the left-hand display can be compared with generalised hypokinesis on the right.

pair suggesting an aneurysm, but not by the other. This involved the apex in three, the anterior wall in two, and the inferior wall in a further three. An example is given in Fig. 4. In four patients, the display showing outward movement was that with end-systole taken as synchronous with aortic valve opening (AVC display), and in four it was with endsystole taken as synchronous with mitral valve opening (MVO display). More commonly, however, discrepancies between the two displays related to apparent regional hypokinesis. In 10, the anterior wall was involved, and in all, the apparent abnormality was present on the MVO display. The inferior wall was involved in six. In three the amplitude of wall motion was lower on the AVC display, and in three on the MVO display. The apex was involved in three cases and, as with the anterior wall, the reduced amplitude of wall motion was seen in the MVO display. Both anterior and inferior walls were involved in three patients.

\section{(4) RELATION BETWEEN TIMING OF} MINIMUM CAVITY AREA AND THAT OF

AORTIC VALVE CLOSURE

Since cavity area increases during isovolumic relaxation, it seemed possible that minimum cavity area might be used to gain some idea of the timing of aortic valve closure if this was not visible on the angiogram. The results are shown in Fig. 5. Though the two were synchronous in 10 patients, there was considerable scatter, with differences of four or five frames, corresponding to time intervals of 80 to $100 \mathrm{~ms}$.

\section{Discussion}

In view of its relative simplicity, the two frame technique seems to have much to recommend it as a means of displaying regional left ventricular wall motion. Indeed, it has been extensively used, and 


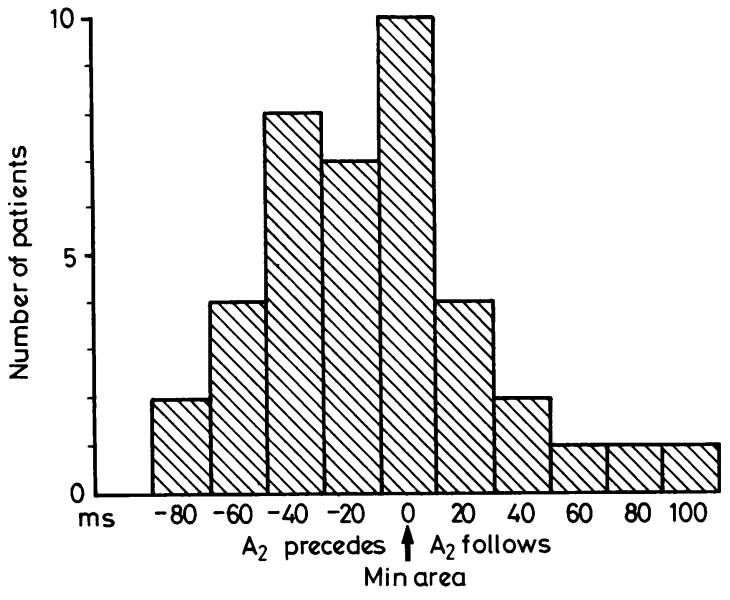

Fig. 5 Histogram plot showing the relation between aortic valve closure and minimum cavity area shown by the arrow.

forms the basis of the classification of abnormal wall movement that is still in widespread use. ${ }^{1}$ It has also been used to express the results of intervention angiography, an increase in the amplitude of regional wall movement resulting from postextrasystolic potentiation, ${ }^{5}$ administration of glyceryl trinitrate, ${ }^{6}{ }^{7}$ exercise, $^{8}$ or catecholamines ${ }^{9}$ being taken as evidence of reversible ischaemia. The method has been used to document acute changes in wall motion brought about by atrial pacing, ${ }^{10}$ and has been elaborated to quantify wall motion along a series of transverse or radial axes using complex data handling techniques. ${ }^{11}{ }^{12}$ It has also been used to assess the results of surgery. ${ }^{13}$

The present results suggest that the interpretation of two frame displays may not be entirely straightforward. Discrepancies caused by variation in the timing of end-systole are the result of changes in cavity shape during the period of isovolumic relaxation. These changes have been studied in detail by a number of authors, ${ }^{314} 15$ and are shown to be of two types. A primary abnormality appears to be prolongation of inward wall movement, behaviour often shown by the myocardium within the territory of a diseased coronary artery. Associated with this is premature outward movement elsewhere in the cavity, usually affecting the anterior wall or, less commonly, the apex. This early outward movement is accompanied by premature thinning of the wall and is not therefore the result of overall movement of the heart in space. ${ }^{16}$ Myocardium showing this behaviour frequently shows normal systolic behaviour, so that its outward movement is assumed to be the result of inward movement else- where in the cavity at a time of constant left ventricular volume.

These considerations stress the difficulty of defining the timing of the end of systole. Changes of cavity shape during isovolumic relaxation indicate that contraction ends asynchronously, being prolonged in those ischaemic areas which show delayed inward movement, and normal, or even short, in those moving outward early. "Systole" thus ends at different times at different places in the cavity, and end-systole as a single event has no meaning. There is no more reason for taking its timing as synchronous with aortic valve closure than with mitral valve opening, and, indeed, with as much reason one could take any other arbitrary time between the two.

The mechanism of changes of shape discussed above has important applications to the determination of the pathological significance of local abnormalities of wall movement. A regional reduction in amplitude is frequently taken as evidence of segmental myocardial disease or depression of function. If the end-systolic frame, however, is taken towards the end of isovolumic relaxation, than an apparent reduction in regional amplitude on a two frame display can result from early outward movement and not from failure of contractile function at all. This was commonly seen in the present series of patients, particularly when it affected the anterior wall or the apex, so that of the 16 cases with apparent hypokinesis affecting these regions, the wall had, in fact, shown normal inward movement during ejection in 13. Uncertainty as to the timing of end-systole can thus lead beyond a simple failure of quantification to misinterpretation of the pathological significance of apparently disturbed wall motion.

Although the major errors resulting from the lack of definition of end-systole come from uncertainty in the detection and interpretation of regional wall motion, a second problem is in the determination of ejection fraction. This is the result of an apparent increase in left ventricular volume immediately before mitral valve opening, as shown by Ruttley and his colleagues. ${ }^{15}$ Ejection fraction is an empirical measurement that is very widely used to assess left ventricular function, yet its significance is not defined in physical terms. Though the correlation coefficient between determinations based on endsystole as aortic valve closure and mitral valve opening was very high, values taken with the latter timing were consistently smaller by approximately 8.5 per cent.

The changes in cavity shape and apparent volume described above are large enough to cause uncertainty in the interpretation of wall motion 
abnormalities in the control state. Though we have not investigated the question in detail, they are large compared with those commonly reported as the result of intervention angiography. If, for example, the display shown in Fig. 3 (left) had followed glyceryl trinitrate administration, a postectopic pause, or even an operation, and that shown in Fig. 3 (right) had represented the control state, then erroneous conclusions might readily be drawn. Similarly, an error in resting ejection fraction of 8.5 per cent would probably not lead to clinical mismanagement, but might be considered significant if it had followed the administration of a drug, or some other intervention. It is clear, therefore, that standardisation is required. We would reiterate (Wiggers ${ }^{17}$ ) that the term end-systole should not be used since it is undefined, and that end-ejection should be substituted. End-ejection can be unambiguously determined from aortic valve closure, and detected non-invasively as the onset of the first high frequency component of the aortic component of the second sound. In the present series, aortic valve closure was visible angiographically in rather a small proportion of patients, but this was a retrospective series, and we have no doubt that the number could have been increased by appropriate positioning and exposure. Unfortunately, the timing of minimum cavity area cannot be rigorously used as a substitute, because of its sensitivity to small errors in the determination of cavity area. We suggest, therefore, that if overall amplitude of wall motion is to be measured, this should be done over a well defined period in the cardiac cycle, preferably ejection. Changes in cavity shape during isovolumic relaxation should be considered separately. The conclusion is difficult to avoid, however, that regional wall motion abnormalities cannot be assessed comprehensively using two frame methods, however elaborate, and that frame by frame analysis is essential for an adequate description of these complex disturbances in patients with ischaemic heart disease.

\section{References}

1 Klein MD, Herman MV, Gorlin R. A hemodynamic study of left ventricular aneurysm. Circulation 1967; 35: 614-30.

2 Tyberg JV, Parmley WW, Sonnenblick EH.In-vitro studies of myocardial asynchrony and regional hypoxia. Circ Res 1969; 25: 569-79.

3 Gibson DG, Prewitt TA, Brown DJ. Analysis of left ventricular wall movement during isovolumic relaxation and its relation to coronary artery disease. Br Heart f 1976; 38: 1010-9.

4 Dodge HT, Sandler H, Baxley WA, Hawley RR. Usefulness and limitations of radiographic methods for determining left ventricular volume. $A m \mathcal{f}$ Cardiol 1966; 18: 10-24.

5 Dyke SH, Cohn PF, Gorlin R, Sonnenblick EH. Detection of residual myocardial function in coronary artery disease using post-extrasystolic potentiation. Circulation 1974; 50: 694-9.

6 Helfant RH, Pine R, Meister SG, Feldman MS, Trout RG, Banka VS. Nitroglycerin to unmask reversible asynergy. Correlation with post coronary bypass ventriculography. Circulation 1974; 50: 108-13.

7 McAnulty JH, Hattenhauer MT, Rösch J, Kloster FE, Rahimtoola SH. Improvement in left ventricular wall motion following nitroglycerin. Circulation 1975; 51 : 140-5.

8 Sharma B, Goodwin JF, Raphael MJ, Steiner RE, Rainbow RG, Taylor SH. Left ventricular angiography on exercise. A new method of assessing left ventricular function in ischaemic heart disease. Br Heart f 1976; 38: 59-70.

9 Horn HR, Teichholz LE, Cohn PF, Herman MV, Gorlin R. Augmentation of left ventricular contraction pattern in coronary artery disease by an inotropic catecholamine. The epinephrine ventriculogram. Circulation 1974; 49: 1063-71.

10 Pasternac A, Gorlin R, Sonnenblick EH, Haft JI, Kemp HG. Abnormalities of ventricular motion induced by atrial pacing in coronary artery disease. Circulation 1972; 45: 1195-205.

11 Harris LD, Clayton PD, Marshall HW, Warner HR. A technique for the detection of asynergistic motion in the left ventricle. Comput Biomed Res 1974; 7: 380-94.

12 Rickards AF, Seabra-Gomes R, Thurston P. The assessment of regional abnormalities of the left ventricle by angiography. Eur f Cardiol 1977; 5: 167-82.

13 Chatterjee K, Swan HJC, Parmley WW, Sustaita H, Marcus HS, Matloff J. Influence of direct myocardial revascularization on left ventricular asynergy and function in patients with coronary heart disease. Circulation 1973; 47: 276-86.

14 Altieri PI, Wilt SM, Leighton RF. Left ventricular wall motion during the isovolumic relaxation period. Circulation 1973; 48: 499-505.

15 Ruttley MS, Adams DF, Cohn PF, Abrams HL. Shape and volume changes during "isovolumetric relaxation" in normal and asynergic ventricles. Circulation 1974; 50: 306-16.

16 Gibson DG, Traill TA, Brown DJ. Changes in left ventricular free wall thickness in patients with ischaemic heart disease. $\mathrm{Br}$ Heart $\mathcal{f}$ 1977; 39: $1312-8$.

17 Wiggers CJ. Studies on the consecutive phases of the cardiac cycle. I. The duration of the consecutive phases of the cardiac cycle and the criteria for their precise determination. $A m$ f Physiol 1921; 56: 415-38.

Requests for reprints to Dr D G Gibson, Cardiac Department, Brompton Hospital, Fulham Road, London SW3 6HP. 